\title{
Moving Toward Active Lifestyles: The Change of Transit-Related Walking to Work From 2009 to 2017
}

\author{
Chia-Yuan Yu and Biyuan Wang
}

\begin{abstract}
Background: This study explored the percentage change of walking to/from public transit to work from 2009 to 2017 in general and for specific sociodemographic characteristics. Furthermore, this study also examined the sociodemographic characteristics of those who walked to/from transit to work and those who walked 30 minutes or more per day to/from transit to work and compared the difference between 2009 and 2017. Methods: 2009 and 2017 National Household Travel Survey were used. This study used weighted logistic regressions to explore the sociodemographic characteristics of those who walked to/from transit to work and those who walked 30 minutes or more per day to/from transit to work in both 2009 and 2017. Results: The percentage of trips achieving the recommended level of physical activity (30 min or more per day) by walking to/from transit work solely has a slightly increase from 9 in 2009 to 9.5 in 2017 . However, the weighted percentages of walking to/from transit to work decreased for low-education, low-income, and minority populations. High population density areas were related to more transit-related walking trips to work in both 2009 and 2017. Conclusions: Policymakers in terms of transit location and service should consider low-education, low-income, and minority populations to address potential equity issues.
\end{abstract}

Keywords: transportation, physical activity, active commute

Public transportation has identified as the means of integrating transit-related physical activity into regular life. ${ }^{1}$ Instead of providing point-to-point travel service, taking public transit requires users to take the trip to the transit station and the trip to the destination. ${ }^{2,3}$ Therefore, the additional trips provide travelers the opportunity to achieve at least 30 minutes of physical activity per day to meet the recommended guidelines of 150 minutes of physical activity per week. ${ }^{3}$ Moreover, due to the low cost of taking public transportation, it is designed for the access to all groups of populations. ${ }^{4}$

Public transportation also provides other benefits such as lower carbon emissions, the reduction of traffic congestion, the improvement of air quality, etc. ${ }^{5-7}$ However, transit service has received relatively low amount of transportation funding than other transportation infrastructure investment. ${ }^{4}$ One of the possible reasons might be the reduction of transit ridership. Although the long-term trend of ridership in the United States has showed a small percentage increase ( $8.5 \%$ in 1980 to $10.2 \%$ in 2016), the transit ridership declined by $3 \%$ specifically from 2014 to 2016 showing a warning of crisis of the transit service. ${ }^{8}$ Thus, with the lower transit ridership, there will also have a relatively percentage of people reaching recommended level of physical activity by transit-related walking.

Previous studies have found the evidence of walking to/from public transit in reaching the recommended level of physical activity. A study using 2001 National Household Travel Survey (NHTS) reported that $29 \%$ of respondents who solely walked to/ from transit achieved 30 minutes or more of physical activity per day. ${ }^{9}$ Another study used 2009 NHTS and found that $40.9 \%$ of workers reached 30 minutes or more of physical activity per day by walking to/from transit to work. ${ }^{10}$ However, we still have limited

Yu is with the School of Public Administration, University of Central Florida, Orlando, FL, USA. Wang is with the Georgia Institute of Technology, Atlanta, GA, USA. Yu (ychiayuan@gmail.com) is corresponding author. knowledge in terms of the change of trend of walking to/from transit from 2009 to 2017 and which specific sociodemographic groups have received the lower benefits of transit-related walking during this trend. Moreover, there is a trend of integrating physical activity into daily life. ${ }^{11}$ Working trips act as a potential opportunity to promote the level of physical activity on the daily basis. ${ }^{12}$ Thus, it is crucial to explore the change of transit-related walking to work and how it could provide recommended amount of physical activity. By exploring this trend, this study could inform policymakers in formulating transit-related policies in providing the equal access to all groups.

This study was to examine the changes in terms of the percentages of walking to/from transit to work, the walk time to/from transit, and the percentage of reaching at least 30 minutes from the walking trip to/from transit to work from 2009 to 2017. Furthermore, this study also investigated the sociodemographic characteristics of those who walk to/from transit to work and those who reached at least 30 minutes of transit-related walking.

\section{Methods}

\section{Data Sources}

The data sources were NHTS 2009 and 2017. These surveys were conducted by the US Department of Transportation. ${ }^{13,14}$ The data were obtained respondent's daily travel from a national stratified random sample of households. ${ }^{15,16}$ The survey aimed the civilian, noninstitutionalized population in the country. The sampling population excluded those living in prisons, rest homes, medical institutions, barracks on military bases, and rooms with 10 or more unrelated people reside. Households must have at least 1 individual aged 18-years-old and older to be eligible for the survey. ${ }^{17}$

A total of 150,147 households in 2009 and 129,112 households in 2017 were eligible to participate the survey. These households were invited to participate by mailing them the survey form 
with an incentive. If they are willing to participate, the invited households could either log into the website or mail the form back. ${ }^{17}$ Therefore, 113,101 households in 2009 and 118,208 households in 2017 participated and responded to the survey.

The sampling method is different between NHTS 2009 and 2017. For 2009, they used a random digit dial telephone sampling and computer-assisted telephone interview data collection. In 2017, they used the address-based sampling and mailing recruitment approach. The reason to change the sampling method is to reduce the burden for respondents. ${ }^{16}$ Moreover, by comparing the estimates in populations and households between 2009 and 2017, it showed that the change in sampling approach had little effect. ${ }^{17}$

Both of the surveys asked the questions about the information on daily travel such as the trip purpose, the travel mode used for each trip, the time from the trip origin to trip destination, and the transportation mode used to get to/from the transit station within a 24-hour period starting at 4:00 AM and ended at 3:59 AM of the following day. It also collected the information regarding individual characteristics, household features, and sociodemographic characteristics. The 2017 NHTS was conducted from March 2016 through May 2017, and 2009 NHTS was from March 2008 through May 2009. To symbolize for the national estimates, NHTS also used the weighting scheme. The weighting scheme is to account for the day of week and month in terms of the travel for the comparisons of weekdays and seasons.

\section{Trip Selection}

The following steps were used to select trips for the transit-related walking to/from transit to work $^{10}$ : (1) trips were conducted by adults (age $\geq 18 \mathrm{y}$ ), (2) the purpose of the trip is to work, (3) trips used public transit as the travel mode, and (4) trips used walking as the mode to/from public transit. Moreover, this study did not include (1) those trips with the missing information regarding trip purpose and the mode used to/from transit, (2) trips that went somewhere else on the way to/from transit to work, and (3) trips that used multiple modes to/from transit. After these selections, a total of 53,187 households in 2009 and 56,430 households in 2017 that have at least 1 adult worker were included to conduct the analyses.

Figure 1 shows the procedure of trip selection and results. After the selection of the trip, $1.8 \%$ of trips in 2009 and $2.3 \%$ of trips in 2017 used transit to work among all trips conducted by adult workers. Among the trips that used transit to work, $54.1 \%$ of them in 2009 and $60.9 \%$ in 2017 were transit-related walking trips. About $9 \%$ of trips in 2009 and $9.5 \%$ in 2017 reached at least 30 minutes of walking to/from transit to work among those trips walking to/from transit to work.

\section{Variables and Measurements}

To explore the sociodemographic characteristics of those who walked to/from transit to work and walked 30 minutes or more per day, this study generated 2 binary variables: (1) whether the respondent walked to/from transit to work among those who used transit to work and (2) whether the respondent achieved 30 minutes or more of walking per day to/from transit to work among those who walked to/from transit to work.

For independent variables, this study considered a variety of sociodemographic characteristics ${ }^{1,2,5,10,18}$ such as race (European American, African American, Asian, Hispanic, and other); gender; age; education level (less than high school, high school,

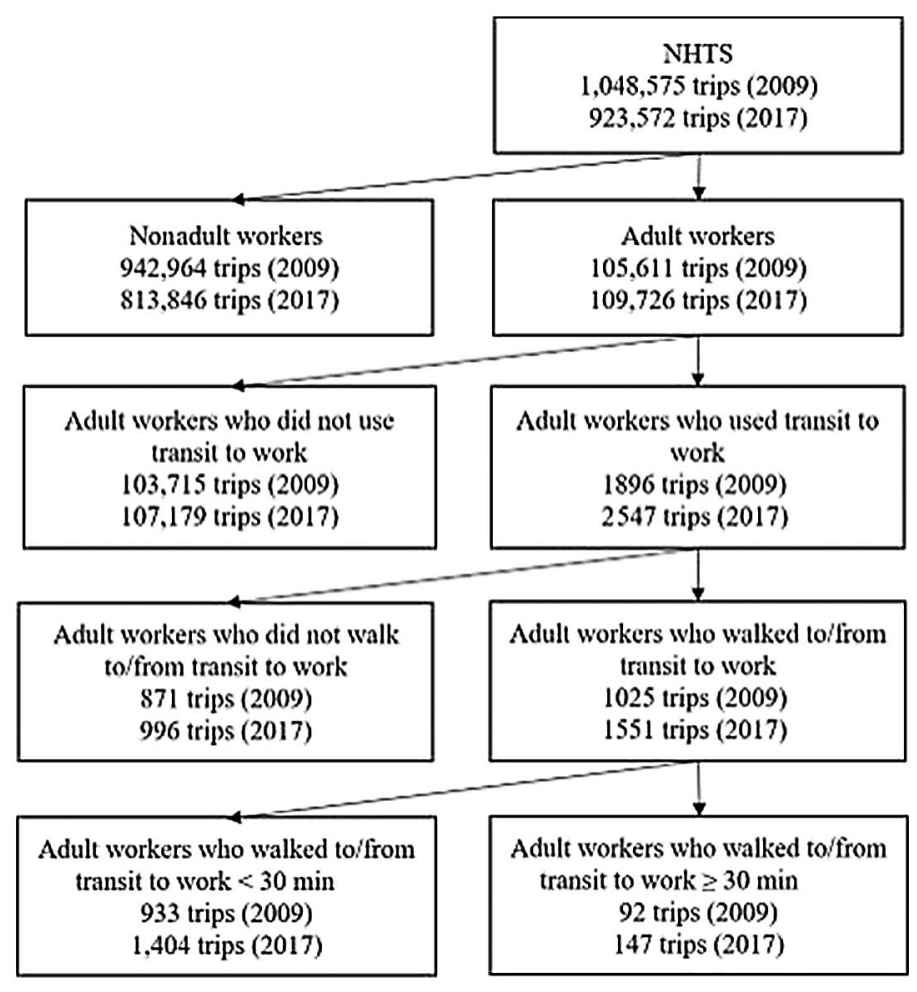

Figure 1 - The procedure of trip selection. Source: 2009 and 2017 National Household Travel Survey.

undergraduate, and graduate); household income $(<\$ 15,000$, $\$ 15,000-\$ 34,999$, \$35,000-\$74,999, and >\$75,000); population density in residence $(<4000$ per square mile, $4000-9999$ per square mile, 10,000-24,999 per square mile, and $\geq 25,000$ per square mile); the number of vehicles owned per household; and the number of household members.

\section{Statistical Analysis}

To symbolize for the national estimates, all the analyses in this study accounted for the sampling weight, and we incorporated the term "weighted" into the analysis that we used. This study conducted the weighted percentage of walking trip to/from transit to work in both 2009 and 2017 and compared and tested the significant change from 2009 to 2017 in specific sociodemographic groups (Table 1). Furthermore, weighted logistic regressions were applied to explore the sociodemographic characteristics of those who walked to/from transit to work and those who walked 30 minutes or more per day to/from transit to work in both 2009 and 2017 (Tables 2 and 3). Moreover, this study calculated the weighted mean of walking time and weighted percentage of achieving 30 minutes or more walking time per day by sociodemographic characteristics (Table 4). This study used Stata 13 (College Station, TX) to perform all the analyses.

\section{Results}

In terms of the weighted percentage of walking to and from public transit to work between 2009 and 2017, the percentage of walking to public transit increased from 73.17 (95\% confidence interval $[\mathrm{CI}], 69.11-77.24)$ to 76.28 (95\% CI, 73.40-79.15), and the 


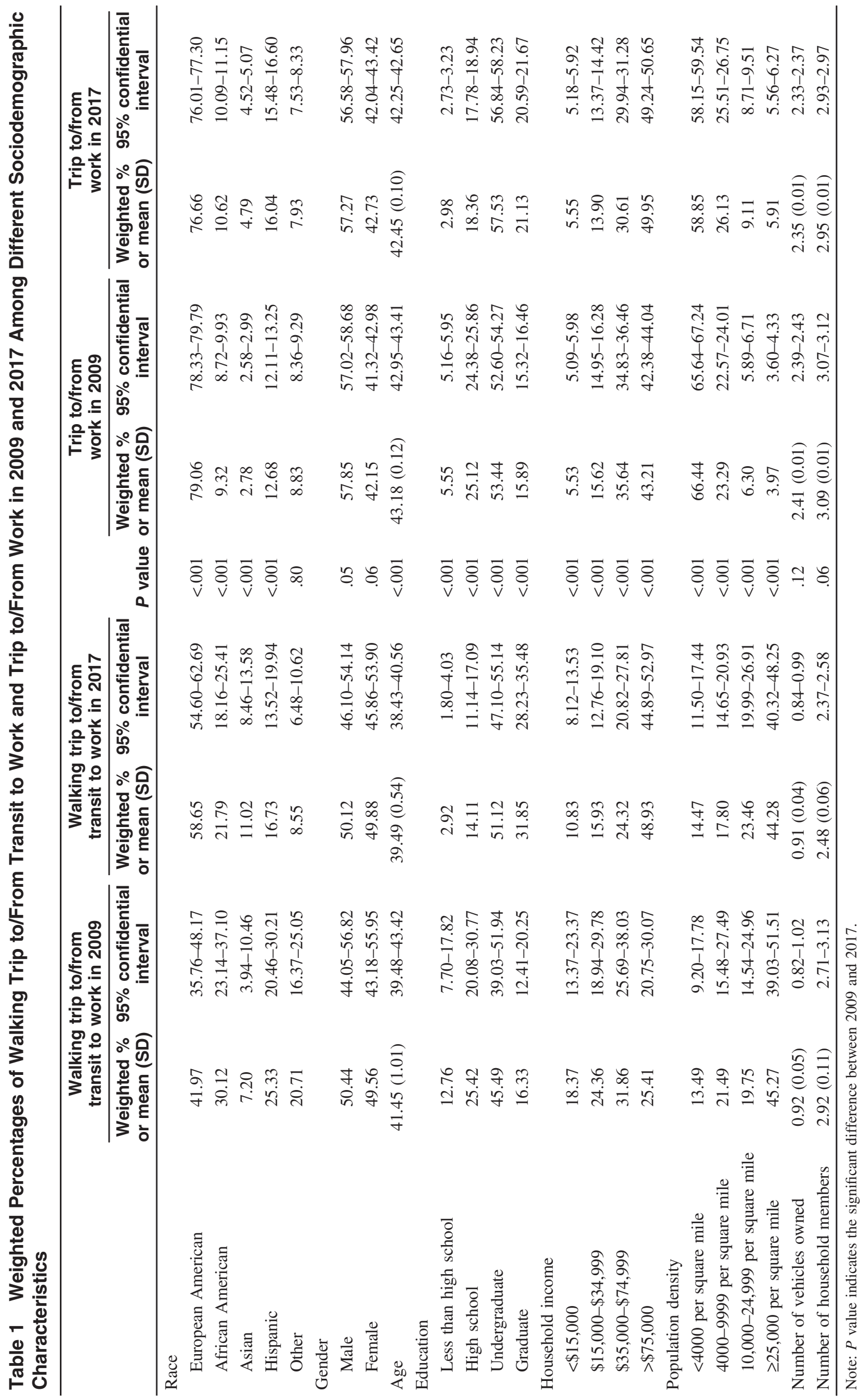


Table 2 Sociodemographic Characteristics of Transit Users Who Walked to/From Transit to Work and Those Who Walked 30 Minutes or More Per Day to/From Transit to Work in 2009

\begin{tabular}{|c|c|c|c|c|c|c|}
\hline & \multicolumn{3}{|c|}{ Walking to/from transit to work } & \multicolumn{3}{|c|}{$\begin{array}{c}\text { Walking } 30 \text { min or more per day to/from } \\
\text { transit to work }\end{array}$} \\
\hline & Odds ratio & $95 \% \mathrm{Cl}$ & $P$ value & Odds ratio & $95 \% \mathrm{Cl}$ & $P$ value \\
\hline \multicolumn{7}{|l|}{ Race } \\
\hline European American & Ref & & Ref & Ref & & Ref \\
\hline African American & 0.80 & $0.57-1.12$ & .19 & 1.32 & $0.70-2.48$ & .39 \\
\hline Asian & 0.98 & $0.64-1.50$ & .93 & 2.07 & $0.89-4.81$ & .09 \\
\hline Hispanic & 1.04 & $0.69-1.56$ & .87 & 1.07 & $0.49-2.34$ & .87 \\
\hline Other & 0.82 & $0.53-1.27$ & .38 & 0.87 & $0.37-2.02$ & .75 \\
\hline \multicolumn{7}{|l|}{ Gender } \\
\hline Male & 1.18 & $0.95-1.47$ & .13 & 1.17 & $0.73-1.88$ & .52 \\
\hline Female & Ref & & Ref & Ref & & Ref \\
\hline Age & $0.99 *$ & $0.98-0.99$ & .01 & 0.99 & $0.98-1.02$ & .90 \\
\hline \multicolumn{7}{|l|}{ Education } \\
\hline Less than high school & 0.84 & $0.49-1.44$ & .53 & 0.83 & $0.29-2.43$ & .74 \\
\hline High school & 1.27 & $0.88-1.85$ & .20 & 1.17 & $0.51-2.66$ & .71 \\
\hline Undergraduate & 0.90 & $0.69-1.18$ & .45 & 1.09 & $0.55-2.14$ & .81 \\
\hline Graduate & Ref & & Ref & Ref & & Ref \\
\hline \multicolumn{7}{|l|}{ Household income } \\
\hline$<\$ 15,000$ & $2.81 * * *$ & $1.73-4.56$ & $<.001$ & $2.36^{*}$ & $0.96-5.80$ & .04 \\
\hline$\$ 15,000-\$ 34,999$ & $2.32 * * *$ & $1.57-3.42$ & $<.001$ & 1.71 & $0.76-3.82$ & .19 \\
\hline$\$ 35,000-\$ 74,999$ & $1.35 *$ & $1.03-1.76$ & .03 & 1.71 & $0.88-3.32$ & .11 \\
\hline$>\$ 75,000$ & Ref & & Ref & Ref & & Ref \\
\hline \multicolumn{7}{|l|}{ Population density } \\
\hline$<4000$ per square mile & Ref & & Ref & Ref & & Ref \\
\hline 4000-9999 per square mile & $1.40 *$ & $1.07-1.83$ & .01 & 0.71 & $0.36-1.41$ & .33 \\
\hline $10,000-24,999$ per square mile & $2.05 * * *$ & $1.50-2.81$ & $<.001$ & 0.83 & $0.41-1.68$ & .61 \\
\hline$\geq 25,000$ per square mile & $5.01 * * *$ & $3.52-7.10$ & $<.001$ & 0.74 & $0.38-1.46$ & .39 \\
\hline Number of vehicles owned & $0.71 * * *$ & $0.62-0.80$ & $<.001$ & 0.93 & $0.71-1.24$ & .64 \\
\hline Number of household members & 0.99 & $0.91-1.09$ & .91 & 0.96 & $0.80-1.15$ & .65 \\
\hline Pseudo $R^{2}$ & & .15 & & & .03 & \\
\hline $\mathrm{N}$ & & 1740 & & & 937 & \\
\hline
\end{tabular}

Abbreviations: CI, confidential interval; Ref, reference group.

$* P<.05 . * * P<.01 . * * * P<.001$

percentage of using private car to public transit decreased from 14.72 (95\% CI, 11.59-17.85) to 14.04 (95\% CI, 11.73-16.35). The percentage of walking from transit decreased from 86.08 (95\% CI, 83.17-88.99) to 78.77 (95\% CI, 75.76-81.78), and the percentage of using private car from transit increased from 0.81 (95\% CI, $0.25-1.37)$ to 1.42 (95\% CI, 0.68-2.15). Moreover, for adult workers, the percentage of walking to/from transit to work increased from 0.97 in 2009 to 1.41 in 2017.

Table 1 presents the weighted percentage of walking trip to/ from transit to work in 2009 and 2017 among different sociodemographic characteristics. Considering the difference of the walking trip to/from transit to work among race, the weighted percentage for European American populations walking to/from transit to work significantly increased from 41.97 (95\% CI, 35.76-48.17) in 2009 to 58.65 (95\% CI, 54.60-62.69) in 2017, whereas the weighted percentage for African Americans (30.12\%-21.79\%) and Hispanics (25.33\%-16.73\%) significantly decreased from 2009 to 2017 . There is no significant difference among the gender. For the education level, the weighted percentage for populations less than high school $(12.76 \%-2.92 \%)$ and high school $(25.42 \%-14.11 \%)$ significantly decreased from 2009 to 2017, whereas the weighted percentage for undergraduate $(45.49 \%-51.12 \%)$ and graduate $(16.33 \%-31.85 \%)$ significantly increased. For the household income, the weighted percentage for low-income populations $(<\$ 15,000$ : $18.37 \%-$ 10.83\%; \$15,000-\$34,999: 24.36\%-15.93\%; \$35,000-\$74,999: $31.86 \%-24.32 \%$ ) significantly decreased from 2009 to 2017, whereas the weighted percentage for high-income populations (>\$75,000: $25.41 \%-48.93 \%$ ) significantly increased. The same pattern appeared between 2009 and 2017 for the population density.

For the walking trips to transit to work, the model results in 2009 and 2017 had the same pattern (Tables 2 and 3). Comparing to the populations with the household income $>\$ 75,000$, populations with income $<\$ 15,000$ (2009: odds ratio $=2.81, P<.001$; 2017: odds ratio $=2.15, P<.001), \$ 15,000$ to $\$ 34,999$ (2009: 
Table 3 Sociodemographic Characteristics of Transit Users Who Walked to/From Transit to Work and Those Who Walked 30 Minutes or More Per Day to/From Transit to Work in 2017

\begin{tabular}{|c|c|c|c|c|c|c|}
\hline & \multicolumn{3}{|c|}{ Walking to/from transit to work } & \multicolumn{3}{|c|}{$\begin{array}{c}\text { Walking } 30 \text { min or more per day to/from } \\
\text { transit to work }\end{array}$} \\
\hline & Odds ratio & $95 \% \mathrm{Cl}$ & $P$ value & Odds ratio & $95 \% \mathrm{Cl}$ & $P$ value \\
\hline \multicolumn{7}{|l|}{ Race } \\
\hline European American & Ref & & Ref & Ref & & Ref \\
\hline African American & $0.58 * * *$ & $0.44-0.76$ & $<.001$ & 1.06 & $0.64-1.77$ & .82 \\
\hline Asian & $0.71 *$ & $0.53-0.96$ & .02 & 0.90 & $0.48-1.69$ & .75 \\
\hline Hispanic & 0.77 & $0.56-1.06$ & .11 & 0.86 & $0.46-1.61$ & .64 \\
\hline Other & 0.71 & $0.50-1.02$ & .06 & 0.89 & $0.44-1.79$ & .74 \\
\hline \multicolumn{7}{|l|}{ Gender } \\
\hline Male & 0.92 & $0.76-1.09$ & .33 & 0.93 & $0.65-1.32$ & .67 \\
\hline Female & Ref & & Ref & Ref & & Ref \\
\hline Age & $0.98 * * *$ & $0.97-0.99$ & $<.001$ & 1.01 & $0.99-1.02$ & .47 \\
\hline \multicolumn{7}{|l|}{ Education } \\
\hline Less than high school & 1.07 & $0.60-1.94$ & .81 & 1.49 & $0.55-4.01$ & .43 \\
\hline High school & 1.25 & $0.89-1.75$ & .20 & 1.29 & $0.69-2.38$ & .43 \\
\hline Undergraduate & 0.87 & $0.71-1.05$ & .15 & 1.18 & $0.78-1.81$ & .44 \\
\hline Graduate & Ref & & Ref & Ref & & Ref \\
\hline \multicolumn{7}{|l|}{ Household income } \\
\hline$<\$ 15,000$ & $2.15^{* * *}$ & $1.45-3.18$ & $<.001$ & $2.05^{*}$ & $1.11-3.77$ & .02 \\
\hline$\$ 15,000-\$ 34,999$ & $1.61 * *$ & $1.17-2.20$ & .003 & 1.25 & $0.71-2.22$ & .44 \\
\hline$\$ 35,000-\$ 74,999$ & $1.55^{* * *}$ & $1.23-1.97$ & $<.001$ & 0.82 & $0.50-1.34$ & .42 \\
\hline$>\$ 75,000$ & Ref & & Ref & Ref & & Ref \\
\hline \multicolumn{7}{|l|}{ Population density } \\
\hline$<4000$ per square mile & Ref & & Ref & Ref & & Ref \\
\hline 4000-9999 per square mile & $1.31^{*}$ & $1.05-1.64$ & .01 & 1.87 & $1.14-3.07$ & .06 \\
\hline $10,000-24,999$ per square mile & $1.90^{* * *}$ & $1.47-2.45$ & $<.001$ & 1.49 & $0.87-2.55$ & .15 \\
\hline$\geq 25,000$ per square mile & $4.35^{* * *}$ & $3.25-5.82$ & $<.001$ & 1.10 & $0.62-1.93$ & .75 \\
\hline Number of vehicles owned & $0.72 * * *$ & $0.66-0.80$ & $<.001$ & 1.17 & $0.96-1.42$ & .12 \\
\hline Number of household members & 0.97 & $0.90-1.05$ & .50 & 1.01 & $0.86-1.19$ & .86 \\
\hline Pseudo $R^{2}$ & & .12 & & & .03 & \\
\hline $\mathrm{N}$ & & 2547 & & & 1551 & \\
\hline
\end{tabular}

Abbreviations: CI, confidential interval; Ref, reference group.

$* P<.05 . * * P<.01 . * * * P<.001$.

odds ratio $=2.32, P<.001 ; 2017$ : odds ratio $=1.61, P<.01)$, and $\$ 35,000$ to $\$ 74,999$ (2009: odds ratio $=1.35, P<.05 ; 2017$ : odds ratio $=1.55, P<.001$ ) were more likely to walk to/from transit to work. Furthermore, comparing to people living in the areas with the population density $<4000$ per square mile, people in the areas with the population densities 4000 to 9999 (2009: odds ratio $=1.40$, $P<.05 ; 2017$ : odds ratio $=1.31, P<.05), 10,000$ to 24,999 (2009: odds ratio $=2.05, P<.001 ; 2017$ : odds ratio $=1.90, P<.001)$, and $\geq 25,000$ (2009: odds ratio $=5.01, P<.001 ; 2017$ : odds ratio $=4.35$, $P<.001)$ were more likely to walk to/from transit to work. People owning more vehicles $(2009$ : odds ratio $=0.71, P<.001 ; 2017$ : odds ratio $=0.72, P<.001)$ were less likely to walk to/from transit to work. For the walking 30 minutes or more per day to/from transit to work, low-income populations $(<\$ 15,000)(2009$ : odds ratio $=$ $2.36, P<.05 ; 2017$ : odds ratio $=2.05, P<.05)$ were more likely to reach 30 minutes of walking per day than high-income populations $(>\$ 75,000)$.
The weighted mean of walking time for African Americans increased from 14.72 in 2009 to 18.01 in 2017, and the weighted percentage of reaching at least 30 minutes for African Americans also increased from 16.14 in 2009 to 29.40 in 2017 (Table 4). However, the weighted mean of walking time for Asians decreased from 22.41 to 15.69 and the weighted percentage of walking $\geq 30$ minutes also decreased from 18.43 to 7.46 . In terms of the education level, the weighted walking mean time for people with the graduate education level did not change dramatically, but the weighted percentage of walking $\geq 30$ minutes increased from 19.03 to 27.60. For those with high household income $(>\$ 75,000)$, the percentage of walking $\geq 30$ minutes increased from 25.32 to 42.92 . For the population density, the percentage of walking $\geq 30$ minutes increased from 13.50 to 31.27 for those in 4000 to 9999 per square mile, 12.60 to 25.32 for those in 10,000 to 24,999 per square mile, and 25.34 to 34.65 for those in $\geq 25,000$ per square mile. 


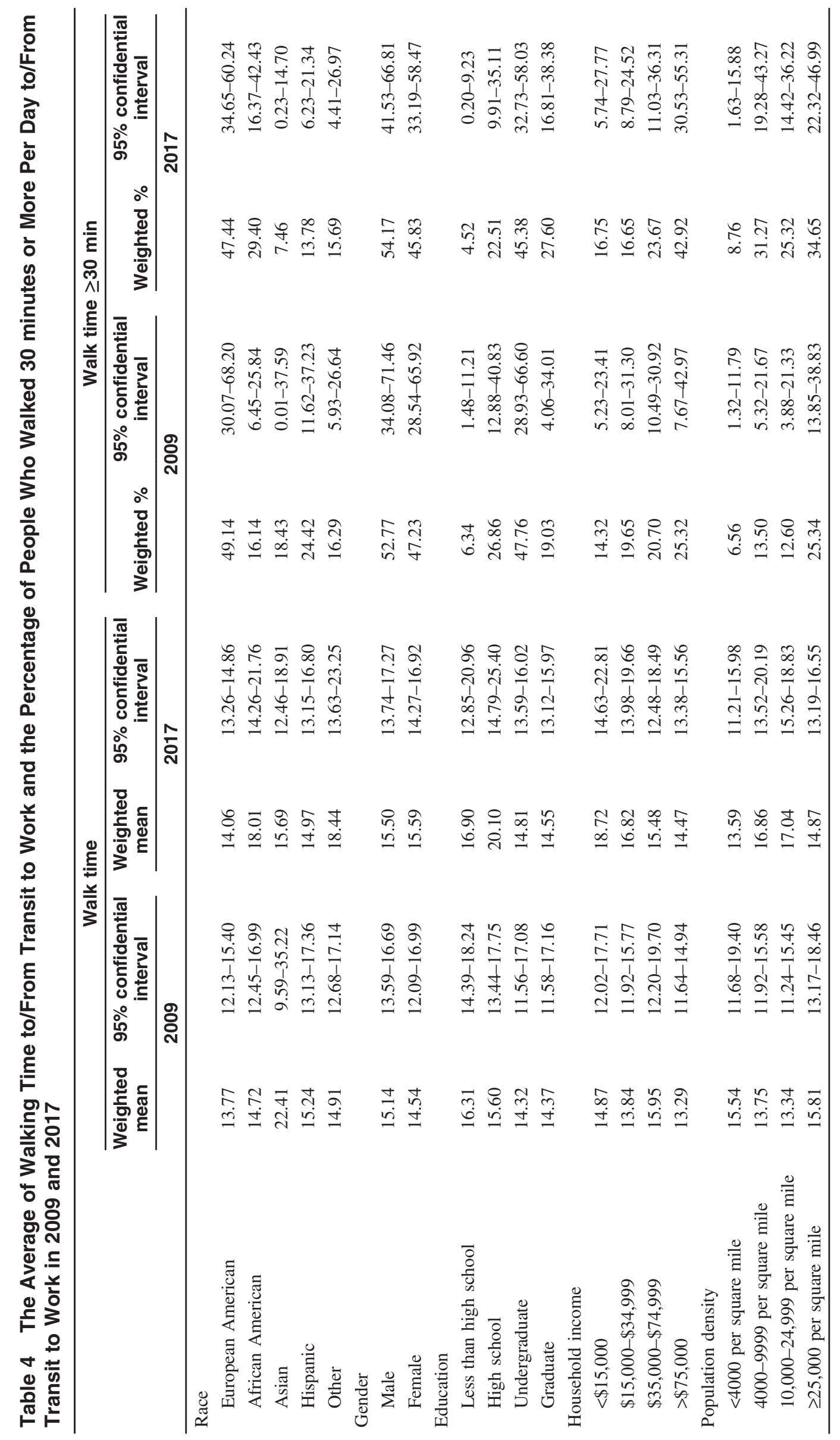




\section{Discussion}

This research revealed the potential benefits of having regular transit-related walking to work in reaching the recommended level of physical activity, which is consistent with previous studies. ${ }^{10}$ Considering the change from 2009 to 2017, the percentage of trips reaching the recommended level of physical activity $(30 \mathrm{~min}$ or more per day) by walking to/from transit work among those trips walking to/from transit to work has a slightly increase from $9 \%$ to $9.5 \%$.

The weighted percentages of walking to/from transit to work have decreased from 2009 to 2017 for low-education populations, but increased for high education groups. One of the possible explanations is that populations with relatively low education level did not recognize the benefits of walking for the health status. ${ }^{18}$ These less educated populations may need more educational programs such as campaigns or incentives to reduce the barriers for walking to/from transit. ${ }^{19}$

Although the low-income and minority populations were more likely to walk to/from transit to work in both 2009 and 2017, the weighted percentages of walking to/from transit to work have decreased from 2009 to 2017. These results have shown the potential equity issue around the transit areas. Previous studies have demonstrated the possibilities of increased property values around transit stations, ${ }^{20,21}$ a situation which cause the housing affordability issues especially for low-income populations if there is no sufficient supplies of affordable housing nearby. ${ }^{22}$ Highincome populations are more likely to move to transit areas and benefit from taking transit, ${ }^{22}$ a possible explanation that might support the increase walking percentage for high-income populations from 2009 to 2017. Considering the transit planning context, it usually benefits certain groups that pay more for the access to transit service. ${ }^{23}$ Therefore, the concept of equity should be considered in the planning process to benefits all groups for the transit service. Moreover, for transit stations in low-income areas, policymakers should consider expand the catchment areas for the walking access to serve those moving farther because of the increased housing prices. ${ }^{1}$

This study found that high population density areas were positively associated with walking to/from transit to work in both 2009 and 2017, which is consistent with previous studies. ${ }^{10}$ High-density areas may feature mixed land use and sufficient pedestrian-friendly infrastructure, ${ }^{24,25}$ providing a walker-friendly environment with multiple daily destinations to support walking behaviors. ${ }^{19}$ Therefore, stations in high-density areas are more likely to produce more walk trips to stations than those in lowdensity areas. ${ }^{19}$

Several limitations have to be mentioned in this study. First, the national survey did not specify the type of transit station such as bus stops or light rail stations. Previous studies reported that people are willing to walk longer distance to light rail stations than to bus stops. ${ }^{1,26}$ It would be interesting for future studies to explore the walking minutes to different types of stations. Second, this study primarily focused on walking as the last mile travel to transit station, more studies could pay attention to biking, and an active travel mode also will promote the level of physical activity. ${ }^{27}$ Third, this study could not account for the potential recall issues because the national survey was self-reported. Finally, because of the change in the sampling method from 2009 and 2017, the comparison might be influenced by this change, although NHTS research team mentioned the influence is little. ${ }^{17}$

\section{Conclusions}

This study used national surveys to explore the percentage change of walking to/from public transit to work from 2009 to 2017 in general and for specific sociodemographic characteristics. Furthermore, this study also explored the sociodemographic features of those who walked to/from transit to work and those who walked 30 minutes or more per day to/from transit to work and compared the difference between 2009 and 2017. Generally, the percentage of people who walked to/from transit to work and who walked at least 30 minutes or more per day has a slight increase from 2009 to 2017. However, for low education, low-income, and minority populations, the percentage decreased. Therefore, policy-making processes in terms of transit location and service should consider these specific populations to address potential equity issues. Further studies should explore the detail in terms of the change of transit-related walking due to the transit infrastructure investment.

\section{References}

1. Durand CP, Tang X, Gabriel KP, et al. The association of trip distance with walking to reach public transit: data from the California Household Travel Survey. J Transp Health. 2016;3(2):154-160. PubMed ID: 27429905 doi:10.1016/j.jth.2015.08.007

2. Djurhuus S, Hansen H, Aadahl M, Glümer C. The association between access to public transportation and self-reported active commuting. Int J Environ Res Public Health. 2014;11(12):1263212651. PubMed ID: 25489998 doi:10.3390/ijerph111212632

3. Rissel C, Curac N, Greenaway M, Bauman A. Physical activity associated with public transport use - a review and modelling of potential benefits. Int J Environ Res Public Health. 2012;9(7):24542478. PubMed ID: 22851954 doi:10.3390/ijerph9072454

4. Sener IN, Lee RJ, Elgart Z. Potential health implications and health cost reductions of transit-induced physical activity. J Transp Health. 2016;3(2):133-140. PubMed ID: 27347481 doi:10.1016/j.jth.2016. 02.002

5. Saelens BE, Moudon A, Kang B, Hurvitz PM, Zhou C. Relation between higher physical activity and public transit use. Am J Public Health. 2014;104(5):854-859. PubMed ID: 24625142 doi:10.2105/ AJPH.2013.301696

6. Litman T. Evaluating Public Transit Benefits and Costs. Victoria, Canada: Victoria Policy Institute; 2014.

7. Beaudoin J, Farzin YH, Lawell CYCL. Public transit investment and sustainable transportation: a review of studies of transit's impact on traffic congestion and air quality. Res Transp Econ. 2015;52:15-22. doi:10.1016/j.retrec.2015.10.004

8. Mallett W. Trends in public transportation ridership: implications for federal policy. Washington, DC: Congressional Research Service; 2018.

9. Besser LM, Dannenberg AL. Walking to public transit: steps to help meet physical activity recommendations. Am J Prev Med. 2005;29(4): 273-280. PubMed ID: 16242589 doi:10.1016/j.amepre.2005.06.010

10. Yu C, Lin H. Transit-related walking to work in promoting physical activity. J Phys Act Health. 2015;12(4):483-489. PubMed ID: 24905190 doi:10.1123/jpah.2013-0342

11. Sallis JF, Linton L, Kraft MK. The first Active Living Research Conference: growth of a transdisciplinary field. Am J Prev Med. 2005;28(2):93-95.

12. Lindström M. Means of transportation to work and overweight and obesity: a population-based study in southern Sweden. Prev Med. 2008;46(1):22-28. doi:10.1016/j.ypmed.2007.07.012 
13. US Department of Transportation. National Household Travel Survey. 2009. http://nhts.ornl.gov. Accessed April 11, 2019.

14. US Department of Transportation. 2017 National Household Travel Survey. 2017. http://nhts.ornl.gov.

15. US Department of Transportation. National Household Travel Survey: user's guide. 2009. https://nhts.ornl.gov/2009/pub/UsersGuideV2.pdf. Accessed April 10, 2019.

16. US Department of Transportation. National Household Travel Survey: user's guide. 2017. https://nhts.ornl.gov/assets/2017UsersGuide.pdf. Accessed April 10, 2019.

17. US Department of Transportation. Summary of travel trends-2017 National Household Travel Survey. 2017. https://nhts.ornl.gov/ assets/2017_nhts_summary_travel_trends.pdf.

18. Yu C, Lin $\mathrm{H}$. Exploring factors regarding transit-related walking and walking duration. J Phys Act Health. 2016;13(11):1220-1229. PubMed ID: 27633619 doi:10.1123/jpah.2015-0667

19. Huang R, Moudon AV, Zhou C, Stewart OT, Saelens BE. Light rail leads to more walking around station areas. J Transp Health. 2017;6:201-208. PubMed ID: 29230382 doi:10.1016/j.jth.2017.02. 002

20. Hess DB, Almeida TM. Impact of proximity to light rail rapid transit on station-area property values in Buffalo, New York. Urban Studies. 2007;44:1041-1068. doi:10.1080/00420980701256005
21. Kay AI, Noland RB, DiPetrillo S. Residential property valuations near transit stations with transit-oriented development. J Transp Geogr. 2014;39:131-140. doi:10.1016/j.jtrangeo.2014.06.017

22. Luckey KS, Marshall WE, Durso C, Atkinson-Palombo C. Residential preferences, transit accessibility and social equity: insights from the Denver region. J Urban. 2018;11(2):149-174.

23. Welch TF, Mishra S. A measure of equity for public transit connectivity. J Transp Geogr. 2013;33:29-41. doi:10.1016/j.jtrangeo.2013.09.007

24. Zhu X, Yu C, Lee C, Lu Z, Mann G. A retrospective study on changes in residents' physical activities, social interactions, and neighborhood cohesion after moving to a walkable community. Prev Med. 2014;69(suppl 1):S93-S97. PubMed ID: 25158208 doi:10.1016/j.ypmed.2014.08.013

25. Smith KR, Brown BB, Yamada I, Kowaleski-Jones L, Zick CD, Fan JX. Walkability and body mass index: density, design, and new diversity measures. Am J Prev Med. 2008;35(3):237-244. PubMed ID: 18692736 doi:10.1016/j.amepre.2008.05.028

26. Daniels R, Mulley C. Explaining walking distance to public transport: the dominance of public transport supply. J Transp Land Use. 2013;6(2):5-20. doi:10.5198/jtlu.v6i2.308

27. Park S, Kang J, Choi K. Finding determinants of transit users' walking and biking access trips to the station: a pilot case study. KSCE J Civil Eng. 2014;18(2):651-658. doi:10.1007/s12205-014-0073-6 